\title{
Corrigendum to "Heat and Mass Transfer Effect on MHD Flow of a Viscoelastic Fluid through a Porous Medium Bounded by an Oscillating Porous Plate in Slip Flow Regime"
}

\author{
S. N. Sahoo \\ Department of Mathematics, Institute of Technical Education and Research, Siksha "O" Anusandhan University, \\ Khandagiri, Bhubaneswar, Odisha 751030, India
}

Correspondence should be addressed to S. N. Sahoo; sachi.sahoo@yahoo.com

Received 28 February 2017; Accepted 5 March 2017; Published 12 July 2017

Copyright (c) 2017 S. N. Sahoo. This is an open access article distributed under the Creative Commons Attribution License, which permits unrestricted use, distribution, and reproduction in any medium, provided the original work is properly cited.

In the article titled "Heat and Mass Transfer Effect on MHD Flow of a Viscoelastic Fluid through a Porous Medium Bounded by an Oscillating Porous Plate in Slip Flow Regime" [1], there were errors as noted in Pantokratoras [2]. The errors are corrected as follows.

(1) In the velocity equation (1st equation) of equations (2), the term $\partial^{3} u / \partial t \partial y$ should be replaced by $\partial^{3} u / \partial t \partial y^{2}$.

(2) In equation (4) the expression $K_{p}=K U_{0}^{2} / v$ should be replaced by $K_{p}=K U_{0}^{2} / v^{2}$ and $M=\sigma B_{0}^{2} v / \rho U_{0}^{2}$ should be replaced by $M^{2}=\sigma B_{0}^{2} v / \rho U_{0}^{2}$.

(3) In equation (5), the term $\partial^{3} u / \partial t \partial y^{3}$ should be replaced by $\partial^{3} u / \partial t \partial y^{2}$.

(4) In the Results and Discussion section, in the description of Figure 6 paragraph, "generative reaction $\left(K_{c}=\right.$ $0)$ " should be replaced by "generative reaction $\left(K_{c}<\right.$ $0) . "$

(5) In Figure 3, the data " $G_{r}=2, G_{m}=2, S_{c}=2$ " for the second curve from the top should be replaced by " $G_{r}=2.5, G_{m}=2, S_{c}=2$ " and the data " $G_{r}=$ $2.5, G_{m}=2, S_{c}=2$ " for the third curve from the top should be replaced by " $G_{r}=2, G_{m}=2, S_{c}=2$ ".

(6) In the description of Figure 3, the statement "The velocity of the flow field decreases due to the increase in the thermal Grashof number" should be replaced by "The velocity of the flow field increases due to the increase in the thermal Grashof number." Also, in the Conclusion section, the statement in the third point (iii) should be replaced by "The velocity of the flow field increases due to the increase in the thermal Grashof number."

\section{References}

[1] S. N. Sahoo, "Heat and mass transfer effect on mhd flow of a viscoelastic fluid through a porous medium bounded by an oscillating porous plate in slip flow regime," International Journal of Chemical Engineering, vol. 2013, Article ID 380679, 8 pages, 2013.

[2] A. Pantokratoras, "Comment on "heat and mass transfer effect on MHD flow of a viscoelastic fluid through a porous medium bounded by an oscillating porous plate in slip flow regime," International Journal of Chemical Engineering, vol. 2017, Article ID 8925828, 2 pages, 2017. 


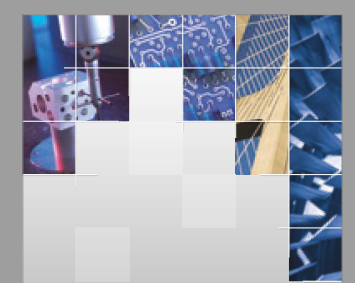

\section{Enfincering}
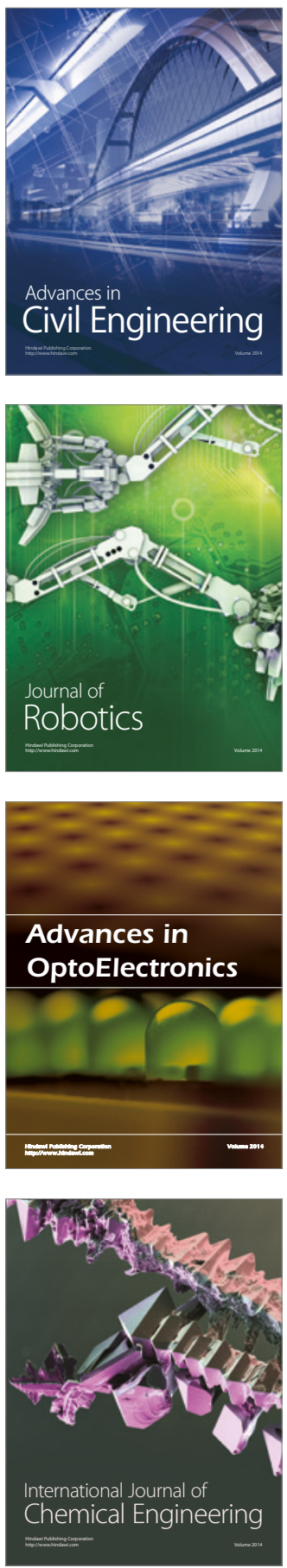

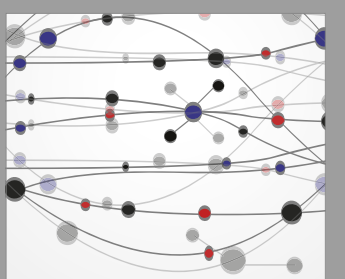

The Scientific World Journal

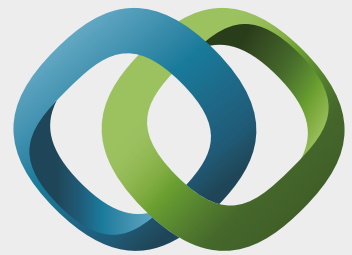

\section{Hindawi}

Submit your manuscripts at

https://www.hindawi.com
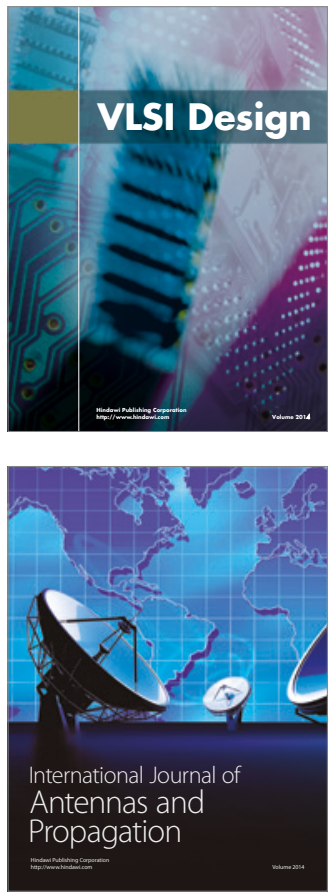

\section{Rotating}

Machinery
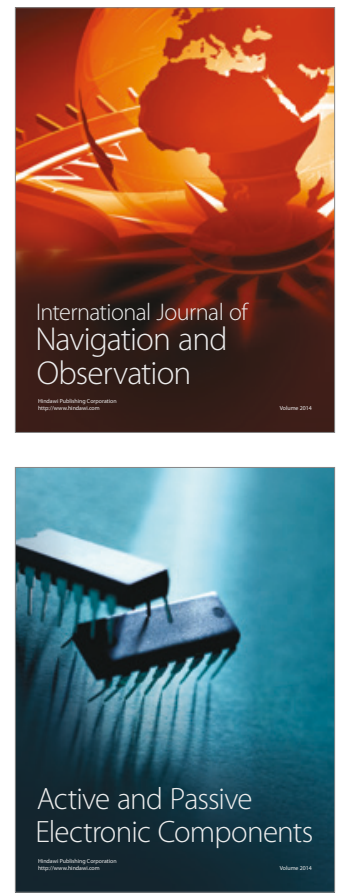
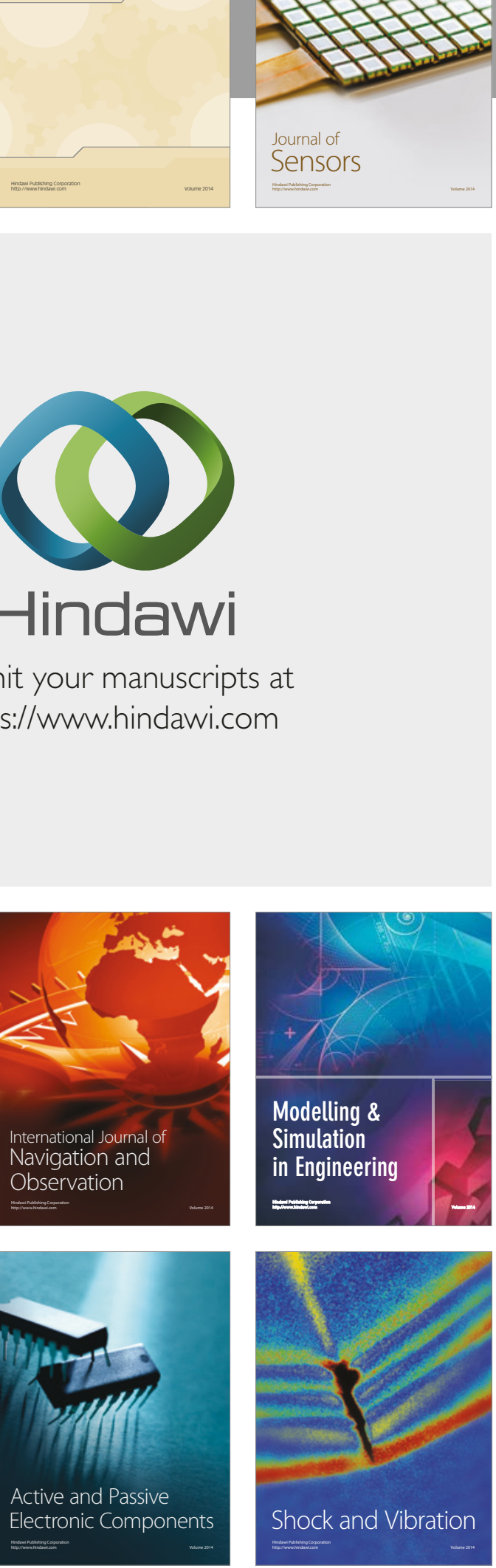
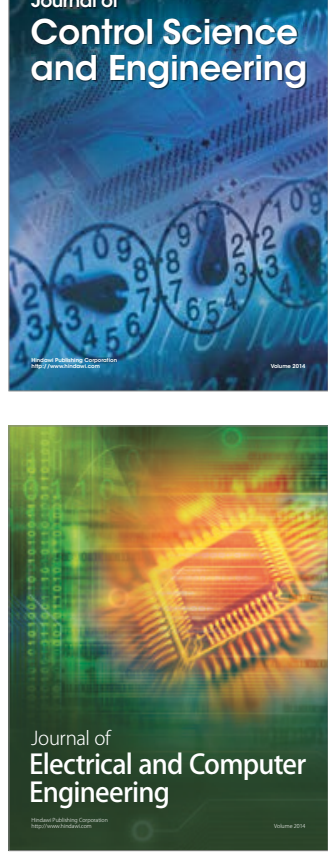

Distributed

Journal of

Control Science

and Engineering
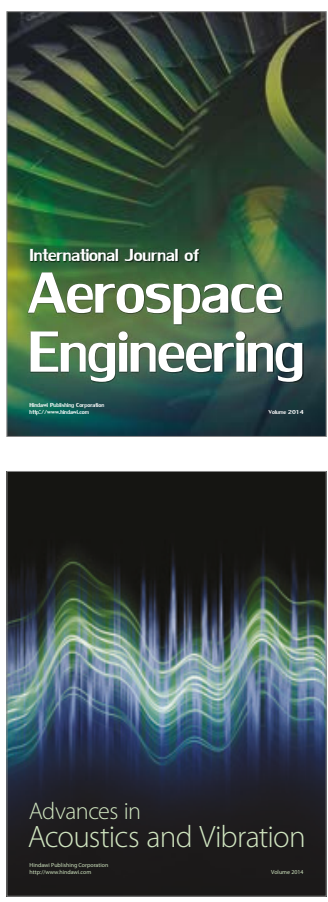

Sensor Networks 